\title{
Government Disaster Policy: Dealing Between Political Will and Political Demands
}

\author{
Maya Mustika Kartika Sari ${ }^{1, *}$ Agus Satmoko ${ }^{2}$ \\ ${ }^{1,2}$ Department of Pancasila and Civic Education, State University of Surabaya \\ "Corresponding author. Email: dwiwardhani24@gmail.com
}

\begin{abstract}
The corona pandemic disaster is a social context that makes policy makers decide various policies to deal with the pandemic. Government policies are the main hope in solving the pandemic problem. Through the functions of regulation, distribution, and control, the government has comprehensive and integrative powers. However, it is often found that there are inconsistencies in the application of government policies originating from different sectors, or between districts and cities. This shows that there are differences in views and orientations in handling the pandemic. It is normal to have differences in policies within government units or bureaucracies between regions, but if this creates disharmony in policy implementation, it is necessary to watch out. This issue has become the focus of discussion in unraveling various problems in synergizing the will and commitment of political leaders and bureaucrats to take action to achieve a set of goals and to maintain political action within the policy framework. The reality of conflicting interests, knowledge frameworks, and rational choice drives distant public decisions. Public policy includes directly or indirectly making ethical judgments. Decisions are made primarily by policy makers through selection and reconciliation of interests represented by individuals, groups and organizations. Public policy is based on a balance of individual and social values. From these values emerge the goals, principles, and styles of implementation and policy interventions.
\end{abstract}

Keywords: Government, Policy, Political Will, Political Demans, Leaders, Decisions, Disaster

\section{INTRODUCTION}

The essence of government policy is a policy aimed at the public in the broadest sense (the state, the community in various statuses and for the public interest), whether it is carried out directly or indirectly, which is reflected in various dimensions of public life. Policy in terms of the choice to do or not to do, implies the existence of a will to do or not to do. Willingness that is expressed based on the authority possessed to make arrangements and if necessary coercion. The statement of will by the authority is associated with policy makers who provide an understanding of the policies carried out by the so-called government. Government policy can be interpreted as a decision of the ruling group or individual state policy makers. If government policy is understood as a regulation whose target is the public, then government policy can be one-way or two-way, it depends on the political system applied.
The public sector can be viewed from various disciplinary perspectives. This is a logical consequence of the broad understanding of the public itself. Management strategy in public policy is understood as a purposive action through setting political agents in identifying and realizing the objectivity of their organizations in their operational environment. The main point is on public agents who compete in the political plurality that exists in their environment. Public agency is a policy subsystem that is part of the system as a whole. It is between these subsystems that competition occurs. From an economic point of view, the public sector is understood as an agent that competes for loyal customers in its activities to fulfill public goods and services. In this case, competition occurs between public/government agencies. The perspective of bureaucratic politics reveals that public agents who were initially policy implementers, in their development expanded two conflicting objectives. On the one hand, it accumulates 
and uses all resources to expand the power and preferences of agencies in public policy, on the other hand, generally creates things related to the common good. There is an attempt to strike a balance between providing political support and opposition, in an effort to maintain his power.

Referring to these three perspectives, the public sector is an entity that bridges the existence of elements in public policy which includes decision makers (politics), bureaucracy (decision implementers), and consumers (public/society). So that the dynamics of the public sector reveal the pattern of relations that occur within the subsystem of public agents (intrasubsystem), between subsystems (intersubsystem), and between other systems, both political and market. The discussion includes regulatory activities consisting of planning, organizing, implementing, monitoring, and budgeting processes. Thus there are two dimensions that make up the public sector, namely the political dimension and the managerial dimension. The political dimension includes the process of setting goals/planning, organizing, and implementing decisions, while the managerial aspects include aspects of supervision/control and budgeting.

The COVID-19 pandemic has become a global issue. In its development, the COVID-19 virus is no longer a health problem, but has turned into a political problem, both on an international, national, and even local level. Political response to the problem of the covid pandemic is unavoidable because politics is the dominant structure that has the legitimacy to regulate other systems through government policies. In Indonesia, policies related to handling the COVID-19 pandemic are reflected in the actions taken by the government at the central level to the regional level.

Social resilience in dealing with this pandemic relies heavily on political commitment to allocate resources to manage and reduce disaster risks and vulnerabilities and build resilience. Lack of political commitment from policy makers can be the cause of delaying priority actions towards hazard mitigation and reducing risks in the short and long term [1]. For this reason, the study of political will is a means of developing synergy among policy makers at all levels of public leadership, in order to aggregate basic values and morals in optimizing various sectors in pandemic management.

The East Java Province experienced a massive increase in the spread of the pandemic. The news reported by Tribun news stated that East Java recorded the highest addition of PDP (patients under monitoring) surpassing DKI Jakarta [2]. The implementation of the PSBB (Large-Scale Social Restrictions) policy set by the East Java governor did not reduce the spread of the corona virus in the East Java region. It can be assumed that there is a possibility of dissynergy among policy makers in East Java, particularly regarding the implementation of large-scale social restrictions. Failure to implement change is generally considered a manifestation of the lack of political will of policy makers [3].

Starting from the background that has been stated previously, the research problem can be formulated as how is the political will of regional policy makers in East Java in interpreting the health emergency of the COVID19 pandemic disaster?

\section{METHODS}

The method used is descriptive qualitative with the type of document/text studies (document studies). Descriptive research is research that describes a symptom, event, and incident that occurs factually, systematically, and accurately. Events that become the center of research will be described without any special treatment given to these events. Qualitative research is to understand social phenomena or phenomena by focusing more on a complete picture of the phenomenon being studied rather than breaking it down into interrelated variables. The hope is to get a deep understanding of the phenomenon so that a theory is then produced. The data are selected according to the research theme and the relationships between the data are analyzed, then concluded. Specifically, the data analysis used is discourse analysis.

\section{RESULTS AND DISCUSSION}

Public policy is a set of decisions by governments and other political actors to influence, change, or frame issues or issues that have been recognized as a political realm by policy makers and/or the wider public [6]. Public policy includes directly or indirectly making ethical judgments. Decisions are made primarily by policy makers through selection and reconciliation of interests represented by individuals, groups and organizations. Public policy is based on a balance of individual and social values. From these values emerge the goals, principles, and styles of implementation and policy interventions. All choices and decisions in public policy at any stage of the policy cycle are ethical judgments because they presuppose that some things are more important than others, that some actions will have a positive and others will have a negative impact on society.

Public policy making related to public health, has become more complex by involving a wider and less predictable interest group including civil society organizations. National governments are also increasingly subject to external and trans-national pressure not only from trans-national corporations, but also from emerging global civil society. While there are widely identified shifts between governments, it is important to keep perspective. While the unrestricted power of many nation states has diminished significantly, 
the state remains influential in initiating, structuring and managing relations between government and civil society actors, including non-governmental organizations. As a result, public health practitioners and advocates need to become experts in the political skills of stakeholder analysis and develop strategic alliances with government officials, professional groups, civil society organizations, donors and the research community if they are to have their policies adopted and implemented. This situation is reflected in the context of making political policies during the current COVID-19 pandemic. The study of political will in handling the pandemic actually reflects the individual and structural readiness of the state apparatus to take political action in the context of realizing the common good.

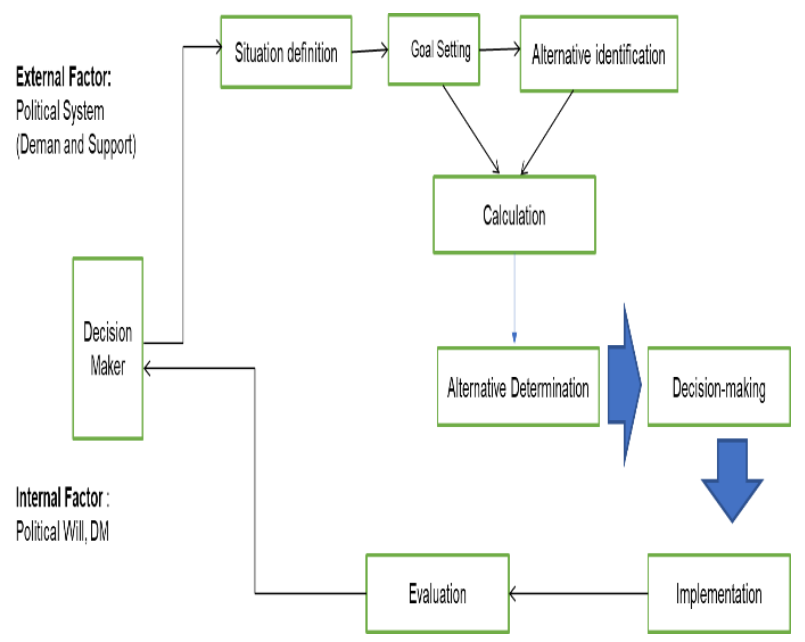

Fig. 1. The Relation of Political Will and Public Policy

In discussing the success or failure of a policy, the term political will (which can be interpreted as political will or will) is often put forward as something that determines the presence or absence of a policy, or things that affect the outcome of a policy. Although it is often unclear what this term means. Political will is generally used as a catch-all concept, meaning it is so vague that it does little to enrich our understanding of the political process and policy. In simple terms, the Oxford political dictionary defines political will as the intention or firm commitment of the government to implement policies, especially policies that are not immediately successful or popular [4]. Meanwhile, Brinkerhoff defines Political Will as the "leader's intention" to do things that are considered necessary for the common good in the long term [5]. Political will is not some kind of enduring and innate personal quality. It is not the same as courage or political conviction. It is a deliberate social construct, and any positive progress of public policy is contingent on its success. This can be summarized in Figure 1.

\section{A.Dimensions of Political Will}

Political will or political will is generally defined as a credible intention shown by political actors [7]. A more detailed and operationally oriented definition of this concept is the commitment of political leaders and bureaucrats to take action to achieve a set of goals and to sustain the costs of those actions over time [8]. This conception shows the complexity of the concept of political will, which involves many dimensions and reflects a large number of underlying factors. Political will can hardly be observed in isolation from the actionsit supports, making it difficult to measure directly. Craig Charney (2009) states that, "Political will is the ghost in the machine of politics, the motive force that generates political action" [9]. Based on this understanding, a number of visible political actions can be assumed as political will or will. Thus political will can be defined as the determination and commitment of individual political actors to do and say things that will produce the desired results. This definition has several important implications.

This definition has several important implications because it omits a number of things. The inability of political or administrative instruments to achieve resultsis excluded. So is the shortage of material resources. Likewise, institutional (or other) barriers and opposition from interest groups that can prevent the desired outcome from occurring. Strengths or weaknesses of individual political actors' determination can sometimes explain an outcome, but are usually much more complicated. Political outcomes are almost always multi-causal, and should avoid common practices including many that have nothing to do with leader determination. This implies that we need to place 'political will' in a number of other features of a given political system if we are to understand what has happened.

Derick and Brinkerhoff suggest several aspects related to political will [10], namely:

- Government initiatives, concerned with the conceptualization, assessment, and moral values that underlie political action.

- Priority Degree. Related to in-depth and empirical studies in determining the main priorities in political action.

- Efforts to mobilize, in this case, are various ways to maximize support and reduce demands.

- Resource allocation, related to cost allocation and monitoring.

- Credible application of sanctions, related to consistency and integrity.

- Learning and adapting, related to consistency of goals in accordance with the context of changes that occur.

\section{B.Knowledge Construction in Disaster Policy}

Decisions, provide a valuable way of framing policy challenges and ambitions. Even if decision theory constructs are ultimately used only informally in practice. Both provide valuable guidance for transparent policy making and addressing severe uncertainty in a sensible manner. First, an attempt to outline a framework to understand and guide decision-making under uncertainty in the context of the COVID-19 pandemic. Second, the facts show how formal decision rules can be used to guide policy making and illustrate their use with the example of school closures. The decision rules we89 
present enable policy makers to recognize that they do not know which of the many potential 'right' scenarios and act accordingly by making careful and decisive decisions that remain valid for various futures and keep options open [11]. Third, we discuss new directions for defining more transparent approaches to communicating the degree of certainty in scientific discoveries and knowledge particularly relevant to decision makers managing pandemics.

The coronavirus (COVID-19) pandemic has exposed various decision constraints faced by the government. Policymakers are tasked with taking action to protect the public from disease, while gaps in the lack of reliable information about the virus and its transmission mechanisms make it difficult to accurately predict the effectiveness of possible actions. Rational policy decisions will incorporate the best available scientific evidence - usually provided by expert opinion and modeling studies - but in an uncertain and rapidly changing environment, evidence is so volatile that it is difficult to produce scientifically based predictions on the results of alternative action.

Given this context, much attention has been paid to how policymakers are handling uncertainty in the COVID-19 response [12]. Policymakers have been faced with different views of potential outbreak scenarios stemming from different expert judgments or different modeling predictions. In the face of such uncertainty, policymakers may respond by trying to balance alternative perspectives, or they may fully embrace one without concern that this could grossly misrepresent our underlying knowledge base [13]. This tendency to lock on to one narrative - or more generally, this inability to handle uncertainty - can result in ignoring valuable insights from alternative sources, and thereby misinterpreting the state of the COVID-19 outbreak, potentially leading to suboptimal decisions with potentially disastrous consequences [14].

There is an important step in setting the agenda, i.e. changes in the introduction of the issue or often put forward to a group of actors of interest and also the actors affected by the change are considered a formal political agenda. This step includes several stages where the next issue is selected later if the capacity in problem solving techniques is not too adequate. In short, issues are able to enter into every community activity, not only regarding objective events, for example: (planning in determining new normal habits) but understanding that can be digested by the mind of the problem and also the description of the problem that can connect to the solution. This variable is known as the key that can influence the ratification of the agenda.

In making needs and also when policies are formulated, it is an important part to consider involving actors in making decisions. The actors will decide something that makes sense and bargain with other actors whose opinions are contradictory and do not agree. The main power of the actor here, is determined by the position of political support they have. Outcomes can be determined by taking the path of the power constellation and also how strong the source of interest is. This stage is known as the 'policy network' which is characterized by non-hierarchical and non-alignment among the actors in the network.

\section{CONCLUSION}

In addition to causing chaos in the community, policies that are not appropriate and implemented will change the order in the government, because the government has issued a number of funds to carry out and also make the program of the policy a success, so that if the policy is remade it will result in over-budgeting. Therefore, in the process of making public policy, policy actors must really review the policy, so that later the policy can truly answer and provide solutions to community problems. Some of the images that can be abstracted are:

- The political response to the pandemic has changed priorities and, as such, the focus and intensity of policy conflicts, but the characteristics and permanence of these changes remain unknown.

- The increasing reliance on scientific and technical expertise in making policy decisions raises questions about political accountability in policy making.

- The pandemic has renewed attention to the importance of, and how little we know about, learning under the stress and urgency of a crisis.

- Given the need to link mass responses and policy decisions, the pandemic reinforces the need to foster understanding in both public policy co-making and coproduction.

- Although we know that basic values and other orientations drive policy success and failure, questions remain about how to handle trade-offs among policymakers.

\section{ACKNOWLEDGMENTS}

This research was supported by the Faculty of Law and Social Sciences, Universitas Negeri Surabaya. Thanks to the Universitas Negeri Surabaya, especially to Dean of the Faculty of Social Sciences and Law. Thank you also to colleagues Lecturer at the Faculty of Social Sciences and Law, Universitas Negeri Surabaya.

\section{REFERENCES}

[1] Jonatan A. Lassa, Akhilesh Surjan, Mely C. Anthony, Rohan Fisherc, "Measuring political will: An index of commitment to disaster risk reduction", International Journal of Disaster Risk Reduction, Volume 34, Maret 2019, hal 64-74. 
[2] https://style.tribunnews.com/amp/2020/05/31/u pdate-virus-corona-nasional-31-mei-25-ribu-kasusjawa-timur-dan-dki-jakarta-tertinggi-kasusbaru?page $=2 \& \_g a=2.133387022 .1235223969 .159$ 0913168-437861055.1516671411

[3] Post, L.A., Raile, A.N.W and Raile, E.D. 2010, Defining Political Will, Politics and Policy, Vol 38, No. 4

[4] Oxford Political Dictinary. 2000

[5] Brinkerhoff, D.W. 2010. "Unpacking the concept of political will to control corruption", U4 Policy Brief, Bergen: Chr. Michelsen Institute and Fritzen, S. 2006. "Beyond 'political will': how institutional context shapes the implementation of anticorruption policies", Policy and Society, Vol 24, No. 3

[6] Anke Hassel, Public Policy, dalam International Encyclopedia of the Social \& Behavioral Sciences (Second Edition), 2015

[7] Malena,C. 2009.From political wont to political will: building support for participatory governance, https://styluspub.presswarehouse.com/resrcs/chapt ers/ 1565493117_excerpt. Pdf

[8] Brinkerhoff, D.W.2000. Assessing political will for anti-corruption efforts: an analytic framework, Public Administration and Development, Vol. 20, No. 3

[9] Craig Charney, Political Will: Whiat is it? How is it Measured?, (New York: Charney Research, 2009)

[10] Derick W. Brinkerhoff, State-Civil Society Networks For Policy Implementation In Developing Countries dalam Review of Policy Research, Volume 16, Issue 1, pages 123-147, March 1999.

[11] Lempert, Robert J, and Myles T Collins. 2007. 'Managing the Risk of Uncertain ThresholdResponses: Comparison of Robust, Optimum, and Precautionary Approaches'. Risk Analysis 27 (4): 1009-1026.

[12] Hansen, Lars Peter. 2014. 'Nobel Lecture: Uncertainty Outside and Inside Economic Models'. Journal of Political Economy 122 (5): 945-987.

[13] Lazzerini, Marzia, and Giovanni Putoto. 2020. 'COVID-19 in Italy: Momentous Decisions and Many Uncertainties'. The Lancet Global Health 8 (5): E641-E642.

[14] Chater, Nick. 2020. 'Facing up to the Uncertainties of COVID-19'. Nature Human Behaviour 4 (439) 